\section{A Santidade como Produto Discursivo na Interpretação do Desenvolvimento Institucional da Igreja Católica: Apontamentos e Reflexões}

\section{Resumo}

A presente reflexão se constrói na tentativa de compreender como o conceito de santidade e seu fundamento podem ser interpretados como uma constituinte da política desenvolvida pela Igreja Católica durante seu desenvolvimento institucional. Nesse sentido, o conceito de Mística é observado a partir da elaboração da santidade de Frei Galvão, como produto discursivo de reação da igreja ao crescimento dos movimentos cristãos Protestantes de início do século XX.

Palavras-chave: Santidade, Discurso, Política, Mística da Reconciliação.

\section{Abstract}

The present reflection is built on the attempt to understand how the concept of holiness and its foundation can be interpreted as a constituent of the politics developed by the Catholic Church throughout its institutional development. In this sense, the concept of Mysticism is observed from the elaboration of Frei Galvão's holiness as a discursive product of the church's reaction to the growth of the Protestant Christian movements of the early twentieth century.

Keywords: Holiness, Discourse, Politics, Mysticism of Reconciliation
Prof. Dr. Eduardo

Antonio Bonzatto

Doutor em História Social pela Pontifícia Universidade Católica de São Paulo.

Prof. Dr. Leandro

Faria de Souza

Doutor em Ciências da Religião pela Pontifícia Universidade Católica de São Paulo. 


\section{Introdução}

O conceito de santidade tem uma importante função no desenvolvimento institucional da Igreja Católica. Este artigo pretende desenvolver uma interpretação crítica em torno desta questão, observando, por meio do discurso, como estes valores atuam e influenciam na formação e na estabilidade institucional da igreja, provocando, ao mesmo tempo, grandes impactos nas populações que ela influencia, afetando desde sua cultura até sua economia.

Para tanto, pretende-se aqui elaborar uma análise e uma aproximação das especificidades históricas na canonização de Antônio Galvão de França: o primeiro Santo brasileiro, e, a partir dela, abrir um debate sobre o discurso aplicado nesse processo histórico como sendo um fundamento político institucional para a cúpula da autoridade católica estabelecida em Roma

O nosso itinerário exige, antes de tudo, uma breve explanação tanto da cronologia do conceito que estamos trabalhando, como da canonização de Frei Galvão. A santidade adquire o seu conceito desde os primórdios do catolicismo como movimento religioso que tem como modelo primordial a figura de Jesus Cristo, permitindo assim a elaboração de uma primeira matriz discursiva em torno de sua representação, principalmente após sua morte.

\section{Origem da Santidade, Fundamento e Nuances}

O primeiro movimento fundamental a ser feito equivale à descrição dos primeiros períodos do cristianismo, para compreendermos como se desenvolveram as ideias que permitiram que a mensagem de Jesus Cristo entrasse em contato com as diferentes culturas da Antiguidade, transformando a sua mensagem universal (FARIA, 2018.p. 28).

Por volta do século primeiro, a região de Jerusalém estava inserida em uma realidade de submissão ao Império Romano. Naquele período, a comunidade judaica presente nesses territórios estava em constante tensão com a autoridade imperial, provocando uma instabilidade política e social que prepararia um terreno fértil para a mensagem inovadora trazida por Cristo.
A grande inovação trazida por Jesus se caracteriza pela sua proclamação como Filho de um Deus único e pela formulação da ação de Deus sobre todas as coisas, em uma visão religiosa oposta da interpretação politeísta oferecida pela tradição greco-romana. Do ponto de vista judaico, as novidades trazidas por ele são consideradas uma afronta a toda tradição rabínica presente até sua época (ALVAR, 1995, p. 86-87).

Estes elementos fazem da figura de Jesus uma ameaça aos valores defendidos pelas autoridades religiosas e políticas de sua época, o que resultaria na sua crucificação. Fato este, que favorece o desenvolvimento de uma mentalidade sacrificial que dá origem à primeira modalidade de santidade: o martírio.

Em linhas gerais, o martírio consiste na perda da vida em nome da defesa da fé. Para os primeiros cristãos, este elemento atuou de forma fundamental para aproximação deles com seu primeiro modelo, Jesus Cristo.

Tendo isso em mente, a história institucional da Igreja Católica está permeada de transformações sociais e políticas que percorrem os mais diferentes contextos históricos, e que fazem dos modelos dos santos, de certa forma, um espelho de cada período analisado, fazendo deles o objeto de uma discussão sobre a importância do discurso no processo de formulação do conceito de santidade.

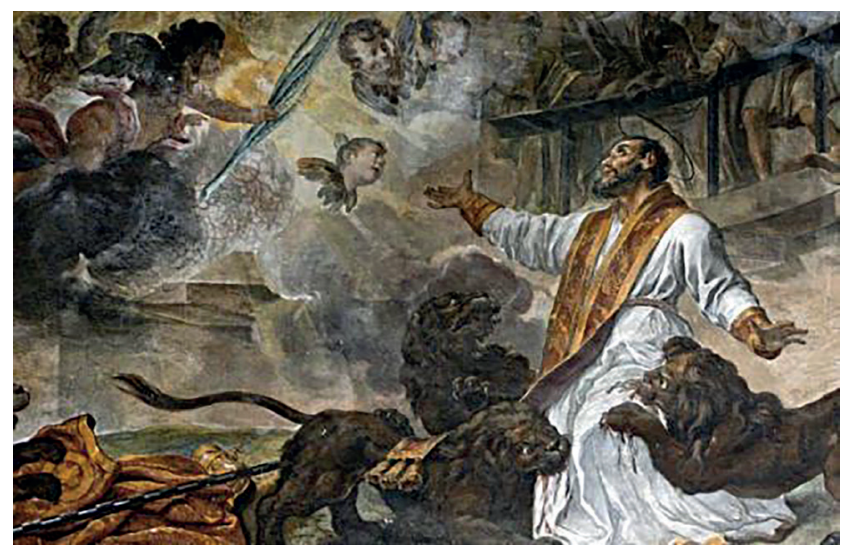

Figura 1 - Santo Inácio Antioquia Bispo e Mártir do Século II $^{\top}$

Fonte: Gaudiumpress

1 GHEZZI, P. Santo Inácio de Antioquia sendo atacado por leões. Igreja de São Clemente, Roma, c. 1700-21. Disponivel em: http://bit.ly/2ZNuwox 
Observando os diferentes períodos históricos, temos o seguinte esquema para compreender o desenvolvimento da santidade em diferentes tempos e o seu significado:

\section{Quadro 1}

\begin{tabular}{|c|c|c|}
\hline Periodo & $\begin{array}{c}\text { Tipo de } \\
\text { Santidade }\end{array}$ & Caracteristicas \\
\hline Séc. I-IV & Martírio & $\begin{array}{l}\text { Imitação de Cris- } \\
\text { to pelo sofrimento } \\
\text { e morte. }\end{array}$ \\
\hline Séc. V-VII & $\begin{array}{l}\text { Culto a } \\
\text { monarcas }\end{array}$ & $\begin{array}{l}\text { Valorização de } \\
\text { figuras régias } \\
\text { como modelos } \\
\text { cristãos. }\end{array}$ \\
\hline Séc. VIII-X & Vida ascética & $\begin{array}{l}\text { Afastamento do } \\
\text { mundo, isolamento } \\
\text { em mosteiros. }\end{array}$ \\
\hline Séc. XI-XIII & $\begin{array}{l}\text { Retorno ao } \\
\text { mundo }\end{array}$ & $\begin{array}{l}\text { Assistência } \\
\text { aos menos } \\
\text { favorecidos } \\
\text { - modelo } \\
\text { franciscano. }\end{array}$ \\
\hline Séc. XIX-XX & $\begin{array}{c}\text { Valorização } \\
\text { da capacidade } \\
\text { sobrenatural } \\
\text { do futuro santo }\end{array}$ & $\begin{array}{l}\text { Diálogo entre } \\
\text { religião e ciência } \\
\text { na comprovação } \\
\text { de curas } \\
\text { milagrosas. } \\
\text { (FARIA, 2018. p.88). }\end{array}$ \\
\hline
\end{tabular}

Do ponto de vista discursivo, esses diferentes modelos representam, em certa medida, a capacidade institucional da Igreja Católica em adaptar-se às mais diferentes necessidades encontradas durante o seu desenvolvimento burocrático, aspecto que favorece uma interpretação voltada à compreensão de como a Santidade é utilizada como ferramenta de reafirmação e de controle por parte da Igreja, que, por meio de seus modelos, amplia a sua área de influência, consolidando parâmetros de comportamento que devem ser seguidos por sua fiel população. Neste sentido, sobre o papel da narrativa e do discurso, Michel de Certeau observa que:

Antes de saber o que a história diz de uma sociedade, é necessário saber como funciona dentro dela. Esta instituição se inscreve num complexo que the permite apenas um tipo de produção e the proíbe outros. Tal é a dupla função do lugar. Ele torna possiveis certas pesquisas em função de conjunturas e problemáticas comuns. Mas torna outras impossiveis; exclui do discurso aquilo que é sua condição num momento dado; representa o papel de uma censura com relação aos postulados presentes (sociais, econômicos, políticos) na análise. Sem dúvida, esta combinação entre permissão e interdição é o ponto cego da pesquisa histórica e a razão pela qual ela não é compativel com qualquer coisa. É igualmente sobre esta combinação que age o trabalho destinado a modificá-la. De toda maneira, a pesquisa está circunscrita pelo lugar que define uma conexão do possível e do impossível. Encarando-a apenas como um "dizer", acabar-se-ia por reintroduzir na história a lenda, quer dizer, a substituição de um não-lugar ou de um lugar imaginário pela articulação do discurso com um lugar social, Pelo contrário, a história se define inteira por uma relação da linguagem com o corpo (social) e, portanto, também pela sua relação com os limites que o corpo impõe, seja à maneira do lugar particular de onde se fala, seja à maneira do objeto outro (passado, morto) do qual se fala. (CERTEAU,1982, p. 75-76)

As ideias trazidas pelo autor consolidam a argumentação que estamos tentando trazer para a nossa reflexão, no sentido de que a santidade se desenvolve a partir de um "jogo" específico de interesses que serviram a Igreja Católica em seu processo de consolidação institucional. Nessa direção, é importante salientar alguns pontos fundamentais que caracterizam o processo de escolha de uma devoção; em nosso caso, utilizaremos os elementos observados na veneração à Frei Galvão e os seus principais traços que fizeram-na ser aceita por parte das autoridades eclesiástica do Vaticano. 


\section{Breve Panorama Histórico de uma Santidade}

Antônio Galvão de França, natural da Cidade de Guaratinguetá, no Vale do Paraíba, SP, nasceu em 1739 e faleceu no dia 23 de dezembro de 1822, na Cidade de São Paulo. Como membro da ordem Franciscana, ele produziu em seu campo de atividade influências que chegaram até nossos dias.

Tradicionalmente, sua figura está diretamente vinculada ao Mosteiro da Luz ${ }^{2}$, importante instituição na história da Cidade de São Paulo, e principal responsável por grande parte de seu prestígio público, fundamental na caracterização de sua santidade.

Um elemento marcante na consolidação da representatividade do religioso, e uma herança deixada por ele para suas protegidas, são as famosas "pílulas" de Frei Galvão, produzidas como o legado perpétuo do franciscano. Sobre essa pílula, sabemos:

\begin{abstract}
Certo dia um moço, que se debatia com fortes dores provocadas por cálculos renais, pediu a Frei Galvão que - abençoasse para ficar livre da dor Frei Galvão, lembrando-se do poder de intercessão da Santíssima Virgem, escreveu em um papelzinho o verso do breviário: "Post partum Virgo inviolata permansisti, Dei Genitrix Intercede pro nobis" e mandou o moço ingerir o papelzinho feito, em forma de pílulas. $\bigcirc$ moço o fez, confiando em Nossa Senhora, e expeliu os cálculos sem dificuldade.
\end{abstract}

Caso semelhante se deu: Frei Galvão foi procurado por um senhor pedindo ajuda para sua mulher, que se achava em grave trabalho de parto e com perigo de vida. Frei Galvão se lembrou do caso do moço curado dos cálcu-

2 Instituição religiosa fundada em 1781 por Irmã Maria Helena do Espírito Santo, e liderada por Frei Galvão, após a morte dela. O religioso também assumiu o projeto arquitetônico do complexo, assim como a função de mentor espiritual das internas do mosteiro. los e deu novamente a este senhor as pílulas de papel com os mesmos dizeres: "Depois do parto, ó Virgem, permanecestes inviolável, ó mãe de Deus, intercedei por nós". Depois de ter ingerido as pílulas, a mulher deu à luz sem dificuldades ou quaisquer problemas. Esta foi a origem ${ }^{3}$ das pílulas. ${ }^{4}$

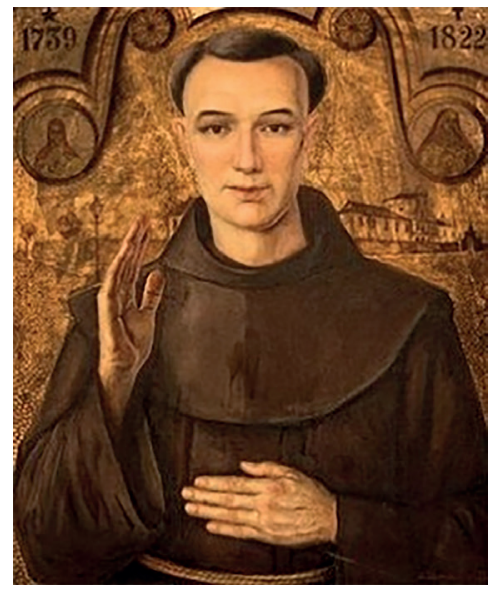

Figura 2 - São Frei Galvão Fonte: CNBB

Prestígio este, que compõe uma importante constituinte em um processo de canonização a chamada fama de santidade, onde se estabelece a importância que determinado candidato à Santo adquire no decorrer de sua vida e, principalmente, após sua morte quando se verifica qual sua relevância para Igreja Católica considerá-lo digno de ser seguido como modelo exemplar: Assim, um homem muito piedoso, cuja vida foi simplesmente edificante, e que foi santificado após sua morte, se espantaria muito se retornasse à vida e pudesse ler sua legenda; esta foi composta, entretanto, com a ajuda de recordacões preciosamente conservadas e redigidas com fé, por aqueles com quem passou parte de sua vida. Nesse caso, é provável

3 Entre os estudiosos de Frei Galvão existe um consenso sobre a provável data de início da produção das pílulas, 1807, muito embora não exista uma comprovação exata disso (cf. o trabalho de ROCHA, M. da. Fé ou placebo? Os efeitos milagrosos das pílulas de Frei Galvão. Dissertação (Mestrado em Ciências da Religião) - Pontifícia Universidade Católica de São Paulo, São Paulo, 2009. p. 33.

4 Relato extraído de: <http://bit.ly/2ZTrOht>. Acesso em: 27 mar. 2018. 
que muito dos acontecimentos recolhidos, e que o santo não reconheceria, não tivessem acontecido; mas alguns deles, que talvez não o tivessem impressionado porque concentrava sua atenção na imagem interior de Deus, impressionaram àqueles que o rodeavam, porque a atenção deles se fixa. (HALBWACHS, 1990, p. 20)

Segundo o autor, a relação estabelecida entre a pessoa virtuosa e seus seguidores provoca o desenvolvimento de traços específicos que marcam essas sociedades em seu modo de ser e de agir, gerando o aprofundamento das raízes identitárias e levando à formação de um conjunto de valores ligados diretamente com a herança deixada pelo santo, tanto material quanto simbólica.

No caso de Frei Galvão, essa caracterização é formulada por meio de uma linha cronológica estabelecida a partir de 1922, ano de celebração do primeiro centenário de sua morte, tendo seu ponto de chegada no ano de 1993 quando da entrada de seu processo de canonização em território romano.

Esta cronologia tem a importante função de demonstrar textualmente e temporalmente que a fama do religioso permaneceu em crescimento durante o período histórico observado, sendo constituída da seguinte maneira:

\section{- 1822-1922:}

- Morte do franciscano e primeiras obras apontando sua relevância;

- Descrever a fama de santidade iniciada pelo Mosteiro da Luz. Período de publicação de sua primeira biografia.

\section{- 1922-1939:}

- Comemoração do Centenário da morte do religioso. Abertura da primeira causa de canonização por Duarte Leopoldo e Silva;

- Caracterizar o aumento de interesse do episcopado de São Paulo em sua canonização.
- 1939-1983:

- Consolidação da imagem pública de Frei Galvão. Abertura do último processo de canonização;

- Centrar a argumentação na descrição da evolução do prestígio público de Frei Galvão, mesmo após um longo período de interrupção do processo.

\section{- Pós-1991:}

- Ampliação da fama de santidade pelo estado de São Paulo (FARIA, 2018, p. 171).

Analisando a estrutura apresentada, é possível notar que os elementos que caracterizam um processo de santificação são basicamente relacionados aos aspectos valorativos defendidos pelo catolicismo desde suas origens, estando permeados de elementos doutrinários e políticos, fazendo da santidade um componente essencial para o diálogo intercultural, fundamento básico para um movimento religioso que se declara universal.

\section{O fundamento discursivo na caracterização de uma santi- dade a partir de Frei Galvão}

A descrição de uma santidade é estruturada a partir de elementos legislativos e simbólicos, que norteiam toda argumentação daqueles que pretendem transformar indivíduo de seu convívio em Santo. De maneira evidente, podemos enumerar a construção da santidade de Frei Galvão por meio das seguintes etapas:

1. O encadeamento de ideias presentes na escrita do processo procura demonstrar que a memória de santidade de Frei Galvão é produto de um longo período de construção; trata-se, portanto, de um processo de longa duração;

2. Como consequência desse processo de longa duração, a linha argumentativa adotada durante a escrita do documento tem por objetivo mapear e distinguir as diferentes regiões em que a trajetória de Frei Galvão serve de modelo para os católicos que solicitam sua intercessão; 
3. Dessa forma, o processo jurídico estrutura a última etapa da construção de uma memória de santidade por meio da descrição da continuidade da popularidade de Frei Galvão e da manutenção do seu número de devotos. Do ponto de vista prático, a visualização deste movimento tem importância crucial no sentido de esclarecer que a mobilização em torno de Antônio Galvão de França continuará fortalecida por tempo indeterminado, caracterizando, assim, essa devoção como uma religiosidade contínua, sem risco de desaparecer.

Portanto, a elaboração do processo de canonização como documento histórico presume a caracterização de um contexto por meio da demonstração da existência de uma memória de santidade, sem a qual não seria possível construir uma linha argumentativa fundamentada e capaz de descrever o percurso de institucionalização da tradição religiosa vinculada a Antônio Galvão de França e seus pares, tanto do Mosteiro da Luz quanto da Ordem Franciscana (FARIA, 2018. p. 187-188).

Essa construção esconde um pano de fundo que muitas vezes não é evidente, representado pelo jogo de forças que ocorre durante o processo de elaboração do documento jurídico de canonização.

Essas forças são responsáveis pelo discurso que é formalizado e aceito pelo Vaticano como verdadeiro, construído por meio de elementos que formam um conjunto de movimentos mentais identitários que dá a cada santo o seu elemento particular e, simultaneamente, à medida que seu movimento de aceitação ocorre, adquire seu caráter universal.

Como consequência, elaboram-se uma série de procedimentos que abrem espaço para a intencionalidade na escrita deste tipo de fonte histórica, constituindo uma importante ferramenta para a compreensão dos fundamentos da Igreja Católica como instituição que faz da santidade o elemento fundamental do discurso teológico e do discurso cotidiano para manutenção do catolicismo e do seu discurso religioso. Nesse sentido temos:
Cristianização da memória e da mnemotécnica, repartição da memória coletiva entre uma memória litúrgica girando em torno de si mesma e uma memória laica de fraca penetração cronológica, desenvolvimento da memória dos mortos, principalmente dos santos, papel da memória no ensino que articula o oral e o escrito, aparecimento enfim de tratados de memória (artes memoriae), tais são os tracos mais característicos das metamorfoses da memória na Idade Média. (LE GOFF, 1990, p. 443)

A interpretação trazida pelo autor francês abre uma perspectiva para inferir a santidade em um elemento mais amplo do que o habitual. Associado aos movimentos devocionais populares, essa ampliação de horizonte, possibilita a análise do papel fundamental que este conceito ocupa na construção de um discurso específico utilizado pela Igreja Católica para manter na sua estrutura certos padrões associados diretamente a uma tradição consolidada e vinculada a uma cultura político-institucional, muitas vezes ligada a políticas adotadas pelo papado que, de alguma forma, norteiam os rumos da Igreja.

Para compreender essa dinâmica, e a importância da argumentação apresentada durante o desenvolvimento de um processo de canonização, é fundamental observar alguns elementos; no caso de Frei Galvão temos os seguintes traços:

- O comportamento valorizado na escrita processual caracteriza Frei Galvão como um modelo ideal para os demais representantes da Igreja no Brasil, e sua herança serve de parâmetro para gerações futuras que irão formar a estrutura administrativa da Igreja em nosso território;

- Sua naturalidade brasileira possibilita a visualização do efeito de sua canonização para a consolidação e o aprofundamento das relações político-institucionais estabelecidas entre o Vaticano e a Cúpula Católica brasileira; 
- A existência de uma memória concreta e organizada favorece o sucesso do projeto de canonização de Antônio Galvão de França e, por consequência, beneficia os grupos sociais envolvidos diretamente nesse processo: a Irmandade do Mosteiro da Luz, a Ordem Franciscana, o Episcopado de São Paulo e a comunidade de Guaratinguetá, ocasionando o fortalecimento institucional de todos os grupos mencionados, principalmente o último, que atualmente usufrui de uma estrutura concreta e simbólica fortalecida após a canonização de Frei Galvão em 2007 (FARIA, 2018, p. 234).

\section{A mística como fundamento da reconciliação}

Frei Galvão foi canonizado em 2007, durante o papado de Bento XVI. É um momento em que a Igreja Católica enfrenta os desafios propostos pelo fortalecimento do pentecostalismo de finais do século $X X$.

O pentecostalismo é um movimento de renovação que surge do interior do cristianismo, em que a experiência direta e pessoal da relação do fiel com Deus acontece por meio do batismo no Espírito Santo.

Nesse sentido, inclui uma enorme variação de perspectivas teológicas e organizacionais. $E$, no Brasil das décadas finais do século XX, disseminou-se em Igrejas como a Assembleia de Deus, a Metodista Wesleyana do Evangelho Quadrangular, a Evangélica do Brasil para Cristo, a Pentecostal Deus é Amor, a Congregação Cristã do Brasil, dentre outras.

Esse crescimento também foi favorecido pelo forçado recolhimento das eclesiais de base resultantes do Concílio Vaticano Segundo, em que a Igreja Católica havia assumido politicamente sua defesa em favor dos pobres.

Se, com João Paulo II, esse abafamento das perspectivas políticas do clero em sua atuação no cone sul já havia sido consideravelmente fortalecido, com Bento XVI se consolidava definitivamente.
O clero conservador que daí adveio teve que enfrentar o recrudescimento das igrejas pentecostais, que prometiam a salvação direta com Deus, pela via do Espírito Santo aliado a valores mais sofisticados de benefícios sociais muito mais tangíveis.

A virada conservadora da Igreja Católica precisou enfrentar esse novo tempo de disputas que, no Brasil, assumiu uma dimensão de difícil compreensão.

O movimento de renovação carismática surge no bojo dessas disputas nos Estado Unidos e, no Brasil, avança definitivamente nos anos 1990. Logo de início, em levantamento quantitativo realizado por Antonio F. Pierucci e Reginaldo Prandi, havia no país cerca de três milhões e oitocentos mil católicos carismáticos, número elevado quase equivalente aos de cristãos protestantes, e já um terço dos pentecostais. Mas era o dobro das comunidades eclesiais de base. Em 2007, ano da canonização de Frei Galvão, estimava-se que eram mais de treze milhões os católicos carismáticos, mas que estimularam um cem número de atividades apostólicas, como comunidades de vida, de aliança, associações de orações, dentre outras. Desde então esse número nunca deixou de crescer.

Importante notar que dentro do movimento pentecostal existe uma vertente que é crescentemente fortalecida, denominada Movimento de Santidade. Esse movimento ensina que a natureza carnal da humanidade pode ser purificada por meio da fé e pelo poder do Espírito Santo, possibilitando que os pecados sejam perdoados pela fé. Sua máxima nos informa que "[...] o dom do Espírito Santo, em sua plenitude pentecostal, não devia restringir-se à igreja apostólica; é um privilégio compartilhado por todos os crentes". Surgiu no final do século XIX, nos Estados Unidos, e se espalhou pelo mundo, principalmente pela América Latina, onde os movimentos neopentecostais tiveram grande expansão e popularidade.

Aqui, a questão da santidade de Frei Galvão ganha um sentido que nos pode revelar muito acerca da política do Vaticano para essa região do mundo, e também para o jogo global em que está agora inserida. 
A figura histórica de Frei Galvão é riquíssima, como, aliás, o é a de todos nós, e um desses lados é que chamarei aqui de A MÍSTICA de Frei Galvão.

Segundo sua biografia, em 1755, ano da morte de sua mãe, assume Santa Ana (Santana), de quem já era devoto, como mãe espiritual (daí seu nome religioso, Frei Antônio de Sant'Ana Galvão). Presume-se que queria ser jesuita, mas por conta da política do Marquês de Pombal, tornou-se franciscano. Em 1770, foi convidado para a Academia Paulistana de Letras, e foi justamente nesse período que recebeu a missão de ser confessor no Recolhimento de Santa Teresa, um recolhimento das devotas de Santa Teresa de Ávila, em São Paulo.

Ali conheceria a Irmã Helena Maria do Espírito Santo, freira penitente que the solicitou a construção de um Recolhimento que ele efetivamente cumpriu, em 1774, fundando o Recolhimento Nossa Senhora da Luz, que daria origem ao bairro da Luz, no centro de São Paulo. A história de sua construção conferiu ao Frei o epíteto de Padroeiro dos Construtores e dos Arquitetos, até hoje associado ao seu nome.

Aqui as linhas se cruzam de modo perturbador para nossas hipóteses. O misticismo de Santa Teresa de Ávila é notório e prevaleceu sobre sua biografia. O cerne desse pensamento místico é a ascensão da alma em quatro estágios.

A chamada teologia mística foi incorporada pela instituição de modo chave, sendo pronunciada no Catecismo da Igreja Católica, e Santa Teresa, que escreveu suas experiências de modo abundante, assume um lugar de destaque dentre os autores dessa linha de pensamento e prática religiosa. Escritora de profunda perspicácia e capacidade analítica, sua definição de oração contemplativa é um registro extremo dessa linhagem: "Oração contemplativa, na minha opinião, é nada mais que um compartilhamento íntimo entre amigos; significa dedicar tempo com freqüência para estar sozinho com aquele que sabemos que nos ama".

5 Catechism of the Catholic Church (parágrafo 2709). Vatican. Disponivel em: http://bit.ly/2ZSGRrs
Desse modo, as quatro partes desse pensamento ganharam permanência no mundo católico. A oração mental, a oração do silêncio, a devoção de união e a devoção do êxtase ou arrebatamento formam o cerne do pensamento místico de Teresa.

\begin{abstract}
Frei Galvão foi um homem de intensa oração e não deve haver dúvidas de seu partilhamento com os princípios devocionais da mística de Teresa de Ávila. Tanto que são inúmeros os fenômenos místicos a ele atribuídos. Dentre esses fenômenos podemos destacar a telepatia, a premonição, a levitação e a bilocação que, segundo relatos permitia que ele estivesse presente em dois lugares diferentes ao mesmo tempo para cuidar de enfermos ou moribundos. ${ }^{6}$
\end{abstract}

A própria pílula de Frei Galvão é marca desse aspecto místico, com a escritura da oração que deve ser ingerida pelo crente.

Papa bento XVI é substituído por Papa Francisco, assumidamente como um franciscano, embora seja um jesuíta e seu nome possa ser derivado de Francisco Xavier, um soldado de Cristo, cuja hagiografia tem traços muito diversos dos de Francisco de Assis.

Esse movimento conservador que a Igreja ingressa no século XXI traz consigo um movimento místico redivivo.

De fato, uma nova teologia mística, fundamentada sobre o princípio que a mística é um fenômeno universal, tem ganho espaço considerado dentre as diretrizes vaticana.

Segundo Karl Rahner, juntamente com o teólogo coreano Ghye-Young Paolo Ko, frade da Ordem dos Frades Menores, o homem católico do século que começa tende a vir a ser um homo mysticus. Rahner chega a afirmar que o cristão de amanhã ou será um místico ou não será um cristão.

6 Cf. FREI GALVÃO. In: Wikipedia. Disponível em: http://bit.ly/2ZNqv3z 
Essa é uma profecia, segundo esses teólogos, que resgata a teologia cósmica universal de Francisco de Assis. Mística significa etimologicamente "[...] fechar os olhos e a boca, pois os olhos devem ser fechados para enxergar somente $o$ segredo e a boca para não se revelar, a não ser no momento ou à pessoa certa".

Deriva do verbo grego MUEIN.

Deste verbo grego MÚEIN deriva o substantivo MISTÉRIO, que designa, no sentido helenístico: o rito religioso secreto de iniciação que coloca em contato o ser humano com a divindade. Na Teologia Espiritual do Novo Testamento, o termo MISTÉRION é usado para elucidar a compreensão do mistério do Reino de Deus, a sabedoria escondida do Pai, a presenca do Filho no mistério da Encarnação, o destino final da caminhada terrena e a relação mística entre Jesus Cristo e a Igreja. Na Vulgata, o termo é traduzido como MISTERIUM ou SACRAMENTUM. Nos primeiros séculos do cristianismo, a palavra não é apenas uma identidade lexical, mas realidade teológica?

A presença da mística passou a ser uma constante nos processos de canonização dos últimos anos. Hildegard Von Bingen, visionária, profeta e mística do séc. XII, que revelava os aspectos femininos de Deus, canonizada também por Bento XVI, ou a canonização de Cunegunda pelo papa João Paulo II. Só em 2013 o Papa Francisco canonizou, junto com a mística italiana Angela de Foligno, outros 800 casos, em que parte deles estão consagrados a aspectos místicos, além dos martírios.

Há uma busca política fundamental neste momento histórico em que a Igreja Católica está imersa: uma busca pela alma dos fiéis e a mística é um aspecto fundamental nesse caminho.

Buscando as palavras do Cristo no Evangetho, pouco antes de sua morte na cruz, "podemos sentir as suas palpitações de amor por nós e o seu desejo de unidade para todos os que creem nele". O Papa Francisco, em sua oração ecumênica de 31 de outubro de 2016, afirma:

7 MAZZUCO, F. V. O que é mística? ALETEIA, 02 out. 2013. Disponível em: http://bit.ly/2ZPaj1O
"Queremos manifestar o nosso desejo comum de permanecer unidos a ele para termos vida", fechando com a reza "Senhor, com a vossa graça ajudai-nos a estar mais unidos a Vós para darmos, juntos, um testemunho mais eficaz de fé, esperança e caridade".

Nesse dia, Papa Francisco reafirma o desejo de que católicos e luteranos caminhem juntos no sentido da reconciliação, reconhecendo que nós "[...] nos fechamos em nós mesmos, com medo ou preconceitos relativamente à fé que os outros professam com uma acentuação e uma linguagem diferentes". E afirmou:

\begin{abstract}
A experiência espiritual de Martinho Lutero interpela-nos lembrando-nos que nada podemos fazer sem Deus. 'Como posso ter um Deus misericordioso?' Esta é a pergunta que constantemente atormentava Lutero. $\mathrm{Na}$ verdade, a questão da justa relação com Deus é a questão decisiva da vida. Como é sabido, Lutero descobriu este Deus misericordioso na Boa Nova de Jesus Cristo encarnado, morto e ressuscitado. Com o conceito "só por graça divina", recordanos que Deus tem sempre a iniciativa e que precede qualquer resposta humana inclusive no momento em que procura suscitar tal resposta. Assim, a doutrina da justificação exprime a essência da existência humana diante de Deus. (Papa Francisco, 2016, s/p)
\end{abstract}

Neste lugar da terra em que Frei Galvão revive seus princípios de união, a sua santificação pode ser um exemplo do desejo institucional dessa busca, em que a alma mística venha a unir todos os cristãos.

\section{Considerações Finais}

Observando tal processo histórico, é possível visualizar que o conceito de santidade extrapola diferentes camadas e períodos do desenvolvimento do cristianismo, e principalmente do catolicismo, tendo ressonâncias em outros movimentos religiosos ligados à figura de Cristo. 
Nessa direção, o desenvolvimento da santidade ocorre em paralelo com as características e os movimentos católicos, protestantes, evangélicos, que assumem interpretações e posturas distintas no decorrer de seus movimentos de separação correlação autoridade vinculada ao Vaticano, ganhando suas dimensões próprias.

Para além destes aspectos concretos, insere-se uma questão fundamental no desenvolvimento dos modelos de comportamento representado como modelo para santidade: as chamadas correntes místicas. Como dito anteriormente, essas interpretações da relação do ser humano com o divino representam, de certa maneira, uma intencionalidade e uma necessidade encontrada pela Igreja Católica para a eleição de seus modelos de santos exemplares, que correspondam às expectativas institucionais de cada contexto vivenciado pelo catolicismo.

Nesse sentido, as circunstâncias enfrentadas pela autoridade do Vaticano, no que diz respeito ao surgimento dos demais movimentos religiosos já citados, exercem uma influência decisiva na transformação da abordagem feita com relação a santidade e seu valor absoluto.

Com esta historicidade em mente, é possível visualizar, no processo de transformação do conceito de santidade, as diferentes facetas que ele adquire, dependendo da função atribuída e de suas consequências políticas para o catolicismo e movimentos religiosos adjacentes, que, em última análise, fazem da santidade uma importante ferramenta de negociações políticas, dando à Igreja Católica a capacidade de modificar seu discurso na contemporaneidade, sem perder suas raízes históricas.

Frei Galvão, nessa perspectiva, tem, em seu processo de santificação, um importante exemplo de uma postura adotada pela Igreja Católica, que teve como objetivo responder a uma conjuntura sócio-religiosa específica, em que, através da autoridade papal, buscou uma resposta ao crescimento dos demais movimentos cristãos em nosso continente, e, por consequência, a tentativa de recuperar um espaço perdido para os pentecostais Protestantes e outras denominações religiosas que floresceram a partir do início do século XX.

Por fim, a santidade, como se pôde perceber neste breve percurso, possui uma importante função na construção e elaboração do discurso produzido e aplicado no catolicismo para sua dinâmica institucional de fortalecimento.

\section{Referências Bibliográficas}

ALVAR, J. et al. (Org.). Cristianismo primitivo y religiones mistéricas. Madrid: Ediciones Cátedra, 1995.

CATECHISM of the Catholic Church. Vatican. Disponivel em: <http://www.vatican.va/archive/ ccc_css/archive/catechism/p4s7c3a1.htm?fbclid=IwAROlY8xeaHuxBwx3TIlyu5wKowSGHrLz_ LBwKDt8EmWGc8AkVQCRQGeZtZ8\#II>. Acesso em: 19 ago. 2019.

CERTEAU, M. de A escrita da história. Trad. Maria de Lourdes Menezes. Rio de Janeiro: Forense Universitária, 1982.

FREI GALVÃO. In: Wikipedia. Disponível em: <https://pt.wikipedia.org/wiki/Frei_Galv\%C3\%A3o>. Acesso em: 19 ago. 2019.

\section{GHEZZI, P. Santo Inácio de Antioquia sendo} atacado por leões. Igreja de São Clemente, Roma, c. 1700-21. Disponível em: <http://www. lourdesalpha.com.br/artigos/santo-inacio-de-antioquia-bispo-e-martir-do-seculo-ii/>. Acesso em: 18 ago. 2019

HALBWACHS, M. A memória coletiva. São Paulo: Vértice, 1990.

LE GOFF, J. História e memória. Trad. Bernardo Leitão [et al.]. 5. ed. Campinas, São Paulo: Editora da Unicamp, 2003.

MAZZUCO, F. V. O que é mística? Aleteia, 2 out. 2013. Disponivel em:<https://pt.aleteia.org/2013/10/02/o-que-e-mistica/?fbclid=IwARORoz8_z1Jyhj-dOdtZ62IIsRU90D3SgoloQEnnhTJr2jP_V-X7gOVyxRg>. Acesso em: 19 ago. 2019. PAPA FRANCISCO. Oração ecumênica: viagem apostólica à Suécia. 2016. 
SOUZA, L. F. de. A construção processual da santidade: abordagem e interpretação da causa de Antônio Galvão de França. Tese (Doutorado em Ciências da Religião) - Pontifícia Universidade Católica de São Paulo, São Paulo, 2018. RÁDIO NOVE DE JULHO. Disponível em: <http:// www.radio9dejulho.com.br/programa/devoto-de-frei-galvao>. Acesso em: 19 ago. 2019.
PJ MONTEMOR. Disponivel em: <https://pjmontemor.wordpress.com/2012/10/25/santo-antonio-de-santanna-galvao>. Acesso em: 19 ago. 2019. 
